Supplement of Atmos. Chem. Phys., 21, 15755-15770, 2021

https://doi.org/10.5194/acp-21-15755-2021-supplement

(C) Author(s) 2021. CC BY 4.0 License.

(c) (1)

Atmospheric

Chemistry

and Physics

Supplement of

\title{
Measurement report: Variability in the composition of biogenic volatile organic compounds in a Southeastern US forest and their role in atmospheric reactivity
}

Deborah F. McGlynn et al.

Correspondence to: Deborah F. McGlynn (mcglyndf@vt.edu) and Gabriel Isaacman-VanWertz (ivw@vt.edu)

The copyright of individual parts of the supplement might differ from the article licence. 
Table S1. Composition and pure concentration of the multi-component calibrant

\begin{tabular}{cc}
\hline Compound & Concentration (ppbv) \\
\hline Pentane & 15.40 \\
Isoprene & 40.30 \\
Methyl Vinyl Ketone & 17.50 \\
Hexane & 9.96 \\
Benzene & 15.00 \\
a-Pinene & 17.60 \\
1,3,5-Trimethylbenzne & 12.40 \\
Limonene & 8.30 \\
Nopinone & 8.92 \\
a-Cedrene & 4.35 \\
a-Humulene & 4.40
\end{tabular}

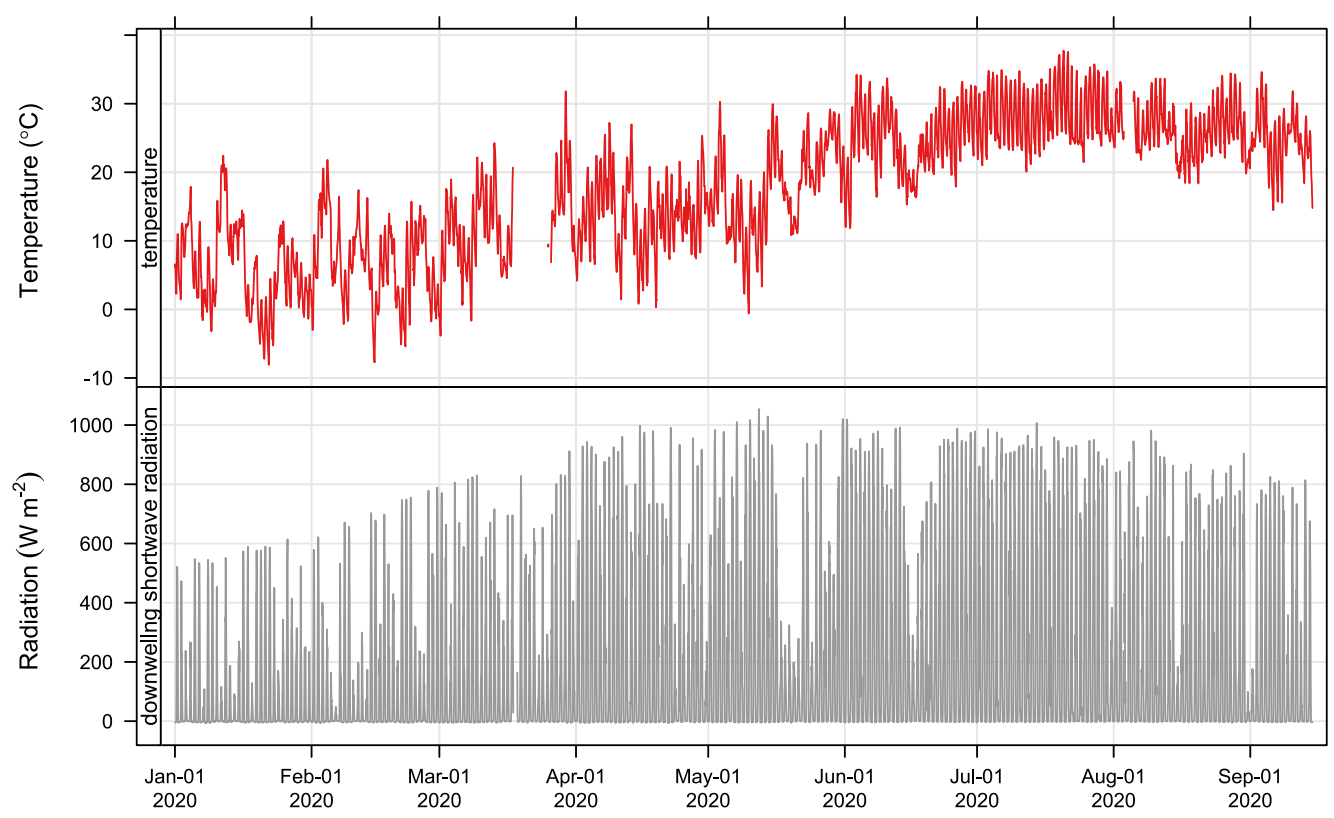

Figure S1. Ambient temperature $\left({ }^{\circ} \mathrm{C}\right)$ and downwelling shortwave radiation $\left(\mathrm{W} \mathrm{m}^{-2}\right)$ for January 2020 - September $15^{\text {th }}, 2020$. 

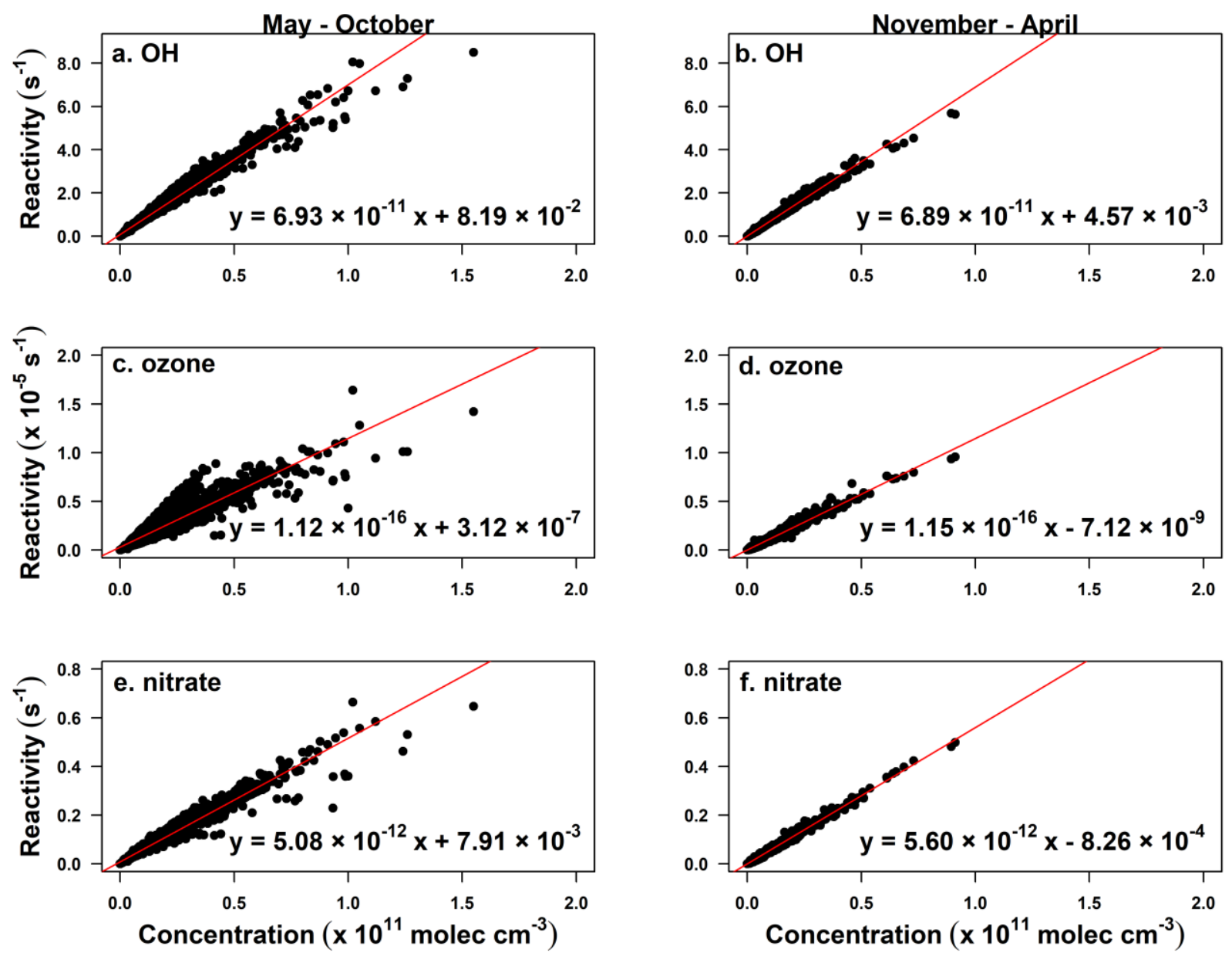

Figure S2. Concentration plotted against reactivity to yield the rate constant for $\mathrm{OH}$ (a-b), Ozone (c-d), nitrate (e-f) in the growing and non-growing season. The slope in each equation is the average reaction rate of each oxidant with total monoterpenes. 